\title{
Physiological Adaptation among Preterm Infants and Associated Maternal Factors
}

\author{
Azza Abdel Moghny Attia ${ }^{1}$ and Nadia Bassuoni Elsharkawy ${ }^{2}$ \\ ${ }^{\prime}$ (Pediatric Nursing Department, Faculty of Nursing, Cairo University Egypt) \\ ${ }^{2}$ (Maternal and Newborn Health Nursing Department, Faculty of Nursing, Cairo University Egypt),
}

\begin{abstract}
Although advances in neonatology led to considerable decreases in preterm infants' mortality and morbidity, the problem is still of major importance. Aim: The aim of this study was to describe the physiological adaptation among preterm infants and explore the associated maternal risk factors. Method: The study was carried out using a prospective descriptive design with follow-up of preterm infants in the Neonatal Intensive Care Unit (NICU) at the Maternity and Children Hospital at Hail, Kingdom of Saudi Arabia. It involved a purposive sample of 60 parturient women in preterm labor and their preterm infants. The data collection tools were a structured interview questionnaire sheet for maternal data and physiological assessment form for preterm infant data. Mothers' age ranged between 18 and 41 years, and their gestational age ranged from 32 to 36 weeks. Results: The results showed statistically significant improvements in preterm infants' blood pressure, anthropometric measurements, skin, and stool characteristics. By day 6, 51.7\% of preterm infants had their length and 50.0\% had their body weight in the normal range for their ages. From day 1 to day 6, respiratory distress syndrome declined from $70.0 \%$ to $21.7 \%$ ( $p<0.001)$. Similarly, the laboratory findings demonstrated statistically significant improvements. The percentage of preterm infants with physiological adaptation increased from $5.0 \%$ at day 1 to $66.7 \%$ at day 6 ( $p<0.001)$. The maternal characteristics associated with physiological adaptation were history of previous abortions $(p=0.02)$, and of stillbirth $(p=0.04)$. As for the current pregnancy, physiological adaptation was associated with multiple pregnancies $(p=0.01)$, and pregnancy-induced hypertension $(p=0.049)$. In multivariate analysis, the independent predictors of physiological adaptation were maternal history of previous abortion and multiple pregnancies. Conclusions: In conclusion, approximately two-thirds of the preterm infants in the study setting had good physiological adaptation by their sixth day of life. The twin pregnancy seems to favor such adaptation, whereas a maternal history of abortion is a risk factor that may hinder it. Thus, infants delivered to mothers with a history of abortion, especially if singleton needs more attention. The difference in adaptation between boys and girls needs further study.
\end{abstract}

Keywords: extra uterine life, maternal risk factors, neonatal intensive care unit, physiological adaptation, preterm infant.

\section{Introduction}

The incidence rates of preterm labor ( $<37$ weeks) varies internationally 5.3 to 11.4 per 100 live births ${ }^{[1]}$, with a majority occurring in Asia and Africa ${ }^{[2]}$, and the rates are rising ${ }^{[3]}$. It is considered as the main cause of neonatal deaths ${ }^{[4]}$ in addition to related disabilities ${ }^{[5]}$ Around a half of preterm births are idiopathic with no identified cause, while approximately one-third is related to premature rupture of membranes, in addition to elective preterm labors, which contribute to $15-20 \%$ of the cases ${ }^{[6]}$. Other possible maternal factors include extremes of reproductive age, lack of proper pregnancy spacing, multiple pregnancies, in addition to other chronic diseases or pregnancy complications, and more frequent use of elective caesarean section ${ }^{[7][8]}$.

In Saudi Arabia in 2010, there were around 35,700 preterm births of whom 2,900 died; and the rate is rising ${ }^{[9]}$. More recently, the preterm birth rate among Saudi women in Jeddah city was $13.7 \%$ of live births ${ }^{[10]}$. Such high rates could be attributed to the high prevalence of maternal risk factors such as very young or old age at pregnancy, which is an established risk factor ${ }^{[11][12]}$, as well as overweight and obesity during pregnancy ${ }^{[13]}$. In addition, there is a high prevalence of diabetes ${ }^{[14]}$.

Preterm infants are exposed to extra-uterine environment before being prepared to. They are functionally immature, and they must rapidly adjust to a normal developmental stage commensurate with their age at the time of birth. Such adjustments may be limited, particularly if exposed to excessive external stimuli and noxious agents that may disturb their hemodynamic and neuroendocrinal adjustment ${ }^{[15]}$. The rate of such adjustment is also variable and may follow different trajectories ${ }^{[16]}$. It is also influenced by certain hormones such as the hormone fibroblast growth factor 21 (FGF21), which lessens postnatal growth in preterm infants ${ }^{[17]}$.

The consequences of delayed or maladaptation of preterm infants may extend to later adulthood. Studies have demonstrated links between their growth impairment and physical ${ }^{[18]}$ as well as psychological and 
personality problems when adult ${ }^{[19][20]}$. Although recent advances in neonatology have considerably decreased preterm infants' mortality and morbidity ${ }^{[21]}$, the problem is still of major importance ${ }^{[22]}$.

1.1 Aim of the study:

The aim of this study was to describe the physiological adaptation among preterm infants and explore the associated maternal risk factors.

\subsection{The research questions:}

1.2.1 How do preterm infants adapt physiologically in their first six days of life?

1.2.2 What is the relationship between risk factors of spontaneous preterm labor and physiological adaptation among preterm infants?

\section{Subjects And Methods}

2.1. Design and setting: The study was carried out using a prospective descriptive design with follow-up of preterm infants for six days after preterm labor. It was conducted in the maternity emergency department and Neonatal Intensive Care Unit (NICU) at the Maternity and Children Hospital, affiliated to the Ministry of Health, at Hail, Kingdom of Saudi Arabia. This free-of-charge unit has a capacity of 72 incubators for dealing with different neonatal health problems.

2.2 Subjects: A purposive sample of 60 parturient women attending the study setting for preterm labor (delivery before 37 weeks of gestation) and their preterm infants who were admitted to the NICU was recruited. Preterm infants who had any congenital malformations were excluded with their mothers.

2.3 Tools for data collection: The researchers used a structured interview questionnaire sheet for maternal data and an assessment form for preterm infant data. The interview sheet included a section for mother's sociodemographic characteristics such as age, level of education, job status, as well as her medical history. It also had a section for the obstetric history, and a last section for the details of the current pregnancy and labor, and any associated complications or problems.

The preterm physiological assessment form was used to record the results of physical assessment (clinical signs) and laboratory findings. The clinical signs assessed were the heart rate, blood pressure, respiration, temperature, muscle tone, cry and reflexes, skin color and turgor, as well as the stool characteristics. It also included some anthropometric measurements such as the head and chest circumferences, length, and weight. There was also a section for assessment of any abnormalities in any of the body systems, with a special emphasis on the signs of respiratory distress syndrome (RDS), necrotizing enterocolitis, and hyperbilirubinemia. The laboratory tests included blood sugar, hemoglobin, hematocrit, White Blood Count (WBC), platelets count, and bilirubin (direct and total).

The data collection tools were prepared by the researchers based on pertinent literature ${ }^{[23][24]}$. They were then rigorously revised by three experts in pediatric and maternity nursing for face and content validity. The tools were finalized after final modifications based on the recommendations and suggestions of the three experts.

2.4 Pilot study: A pilot study is carried out on six mothers and their preterm infants to test the practicability and applicability of the tools. Only very minor modifications were done based on the findings obtained from the pilot study. The pilot sample was included in the main study sample.

2.5 Study maneuver: An official approval of the study protocol was obtained from the ethics committee of the College of Nursing, Hail University. A permission to conduct the study was also secured from authorized officials at the Maternity and Children Hospital. A written consent was obtained from each mother after full explanation of the study purpose and maneuvers. The form clarified participant's rights to refuse or withdraw from the study at any time, in addition to the confidentiality of any obtained information.

The mother who signed the consent form was then interviewed by one of the researchers using the structured interview sheet. This was done in the emergency room before admission. Mothers' age ranged between 18 and 41 years with mean $29.0 \pm 5.6$ years; slightly more than one-third $(36.7 \%)$ were illiterate, and $71.7 \%$ were housewives. As regards their obstetric history, $75.0 \%$ were multigravida and 33.3\% multipara; around one-third of them gave a history of cesarean section (35\%), abortion (30\%), stillbirth $(28.3 \%)$, and $20.0 \%$ had preterm labor. The current pregnancy gestational age ranged from 32 to 36 weeks. Almost majority of mothers (95\%) had pregnancy complications, mainly vaginal and urinary tract infections, and antepartum hemorrhage.

The preterm infant was identified by his/her mother name. The majority (78.3\%) had a gestational age 32 to 35 weeks. Slightly more than half of them were delivered by cesarean section $(53.3 \%)$. They were equally distributed by gender. Physical assessment of the infant was done by another researcher using the designated form. Then, the laboratory data were transcribed from the infant's medical record. This was repeated daily by one of the researchers during the six-day follow-up period. Reflexes were assessed based on the NICU policy using a 3-point scale: two for normal, one for weak, and zero for absent. Reflexes were assessed at the end of day one and day six from the date of delivery to ensure the stability of preterm infant condition.

2.6 Statistical analysis: Data entry and statistical analysis were done using SPSS 20.0 statistical software package. Qualitative categorical variables were compared using chi-square test. Whenever the expected values 
in one or more of the cells in a $2 \times 2$ tables was less than 5, Fisher exact test was used instead. In order to identify the independent predictors of physiological adaptation, multiple logistic regression analysis was used. Statistical significance was considered at p-value $<0.05$.

\section{Results}

Table 1 indicates improvements in almost all parameter of the preterm infants between day 1 and day 6 of their lives. These reached statistical significance concerning normalization of their blood pressure, anthropometric measurements, skin, and stool characteristics. Meanwhile, all preterm infants had normal blinking, rooting, extrusion, and tonic neck reflexes from the first day. Additionally, a great majority of them had normal respiratory rate at day $1(91.7 \%)$, and this rose to $95.0 \%$ at day 6 , but the difference was not statistically significant. Similarly, the percentage of preterm infants with normal body temperature increased from $71.7 \%$ at day 1 to $85.0 \%$ at day 6 , but the difference did not reach statistical significance $(\mathrm{p}=0.08)$. Moreover, by day 6 , around half of the preterm infants had their length $(51.7 \%)$ and body weight $(50.0 \%)$ in the normal range for their ages.

As regards the problems facing the preterm infants from day 1 to day 6, Table 2 illustrates that the most commonly encountered ones were those related to the gastrointestinal (75.0\%) and respiratory $(70.0 \%)$ systems. However, these problems demonstrated statistically significant decreases from day 1 to day 6 . Thus, the percentage of preterm infants with Respiratory Distress Syndrome (RDS) declined from $70.0 \%$ to $21.7 \%$ $(\mathrm{p}<0.001)$. Similarly, the percentages of preterm infants with abnormal laboratory findings demonstrated statistically significant decreases between the first and sixth days, except only for the platelets count and direct bilirubin. Overall, the percentage of preterm infants with physiological adaptation (defined as absence of abnormal physical findings or laboratory results) increased from $5.0 \%$ at day 1 to $66.7 \%$ at day 6 , and the difference was statistically significant $(\mathrm{p}<0.001)$.

Table 3 shows that only two of the maternal characteristics had a statistically significant association with preterm infant's physiological adaptation. These were the history of previous abortions $(p=0.02)$, and of stillbirth $(\mathrm{p}=0.04)$. It is evident that higher percentages of the preterm infants who had no physiological adaptation were born to mothers having history of previous abortion of stillbirth. None of the other maternal factors had a significant association with preterm infant physiological adaptation.

As regards the current pregnancy and labor characteristics and their relations to preterm infant physiological adaptation, Table 4 points to statistically significant associations with multiple pregnancy $(\mathrm{p}=0.01)$, and pregnancy-induced hypertension $(\mathrm{p}=0.049)$. It can be noticed that a higher percentage of the preterm infants with physiological adaptation was from multiple pregnancies, i.e. twins. Conversely, more preterm infants with no physiological adaptation were born to mothers having pregnancy-induced hypertension. Although higher percentages of the preterm infants with no physiological adaptation were born to mothers having <24-month pregnancy spacing, and were males, the differences did not reach statistical significance, $\mathrm{p}=0.06$ and $\mathrm{p}=0.10$, respectively.

In multivariate analysis (Table 5), the independent statistically significant predictors of preterm infant physiological adaptation turned to be the maternal history of previous abortion as well as the multiple pregnancy. It is evident from the table that the history of previous abortion decreases the odds of physiological adaptation, i.e. a risk factor. On the other hand, multiple pregnancies are increases the odds of physiological adaptation, i.e. a protective factor.

Table 1: Comparison of vital and physical signs among preterm infants on Day 1 and Day 6

\begin{tabular}{|c|c|c|c|c|c|c|}
\hline \multirow[t]{3}{*}{ Normal } & \multicolumn{4}{|c|}{ Day } & \multirow[t]{3}{*}{$\mathrm{X}^{2}$ test } & \multirow[t]{3}{*}{ p-value } \\
\hline & \multicolumn{2}{|c|}{1} & \multicolumn{2}{|c|}{6} & & \\
\hline & No. & $\%$ & No. & $\%$ & & \\
\hline Systolic blood pressure & 36 & 60.0 & 52 & 86.7 & 10.91 & $0.001^{*}$ \\
\hline Diastolic blood pressure & 32 & 53.3 & 52 & 86.7 & 15.87 & $<0.001 *$ \\
\hline Respiratory rate & 55 & 91.7 & 57 & 95.0 & Fisher & 0.71 \\
\hline Temperature & 43 & 71.7 & 51 & 85.0 & 3.14 & 0.08 \\
\hline Cry & 31 & 51.7 & 37 & 61.7 & 1.22 & 0.27 \\
\hline Muscle tone & 39 & 65.0 & 39 & 65.0 & 0.00 & 1.00 \\
\hline \multicolumn{7}{|l|}{-Reflexes: } \\
\hline Grimace, cough sneeze & 32 & 53.3 & 38 & 63.3 & 1.23 & 0.27 \\
\hline Blink & 60 & 100.0 & 60 & 100.0 & 0.00 & 1.00 \\
\hline Routing & 60 & 100.0 & 60 & 100.0 & 0.00 & 1.00 \\
\hline Sucking & 47 & 78.3 & 42 & 70.0 & 1.09 & 0.30 \\
\hline Swallowing & 51 & 85.0 & 43 & 71.7 & 3.14 & 0.08 \\
\hline Extrusion & 60 & 100.0 & 60 & 100.0 & 0.00 & 1.00 \\
\hline Tonic & 60 & 100.0 & 60 & 100.0 & 0.00 & 1.00 \\
\hline Palmar grasp & 59 & 98.3 & 53 & 88.3 & Fisher & 0.06 \\
\hline Moro & 26 & 43.3 & 22 & 36.7 & 0.56 & 0.56 \\
\hline
\end{tabular}


Physiological Adaptation among Preterm Infants and Associated Maternal Factors

\begin{tabular}{|c|c|c|c|c|c|c|}
\hline Babinski & 27 & 45.0 & 23 & 38.3 & 0.55 & 0.46 \\
\hline Step in place & 12 & 20.0 & 10 & 16.7 & 0.22 & 0.64 \\
\hline Have all reflexes & 25 & 41.7 & 33 & 55.0 & 2.14 & 0.14 \\
\hline Head circumference & 17 & 28.3 & 31 & 51.7 & 6.81 & $0.01 *$ \\
\hline Chest circumference & 4 & 6.7 & 29 & 48.3 & 26.12 & $<0.001^{*}$ \\
\hline Length & 3 & 5.0 & 31 & 51.7 & 32.18 & $<0.001^{*}$ \\
\hline \multicolumn{7}{|l|}{ Body weight: } \\
\hline Normal & 5 & 8.3 & 30 & 50.0 & & \multirow[t]{4}{*}{$<0.001^{*}$} \\
\hline Low birth weight & 50 & 83.3 & 25 & 41.7 & $24.30^{@}$ & \\
\hline Very low birth weight & 4 & 6.7 & 4 & 6.7 & & \\
\hline Extremely low birth weight & 1 & 1.7 & 1 & 1.7 & & \\
\hline Skin characteristics & 0 & 0.0 & 26 & 43.3 & 33.19 & $<0.001 *$ \\
\hline \multicolumn{7}{|l|}{ Stool: } \\
\hline Meconium & 49 & 81.7 & 32 & 53.3 & & \multirow[t]{3}{*}{$0.002 *$} \\
\hline Greenish & 9 & 15.0 & 16 & 26.7 & 12.67 & \\
\hline Normal & 2 & 3.3 & 12 & 20.0 & & \\
\hline
\end{tabular}

(@) Test between normal and abnormal weight

(*) Statistically significant at $p<0.05$

Table 2: Comparison of health problems and lab tests among preterm infants on Day 1 and Day 6

\begin{tabular}{|c|c|c|c|c|c|c|}
\hline & \multicolumn{4}{|c|}{ Day } & \multirow[t]{3}{*}{$\mathrm{X}^{2}$ test } & \multirow[t]{3}{*}{$\mathrm{p}$-value } \\
\hline & \multicolumn{2}{|c|}{1} & \multicolumn{2}{|c|}{6} & & \\
\hline & No. & $\%$ & No. & $\%$ & & \\
\hline \multicolumn{7}{|l|}{ Problems: } \\
\hline $\begin{array}{l}\text { GI (vomiting, stomach residue } \\
\text { and abdominal distension) }\end{array}$ & 45 & 75.0 & 31 & 51.7 & 7.03 & $0.008^{*}$ \\
\hline RDS & 42 & 70.0 & 13 & 21.7 & 28.23 & $<0.001 *$ \\
\hline Sepsis & 3 & 5.0 & 1 & 1.7 & Fisher & 0.62 \\
\hline Necrotizing enterocolitis & 1 & 1.7 & 0 & 0.0 & Fisher & 1.00 \\
\hline Hyperbilirubinemia & 5 & 8.3 & 8 & 13.3 & 0.78 & 0.38 \\
\hline Anemia & 1 & 1.7 & 0 & 0.0 & Fisher & 1.00 \\
\hline \multicolumn{7}{|l|}{ Abnormal tests: } \\
\hline Blood sugar & 15 & 25.0 & 5 & 8.3 & 6.00 & $0.01 *$ \\
\hline Hemoglobin & 14 & 23.3 & 2 & 3.3 & 10.38 & $0.001 *$ \\
\hline Hematocrit & 24 & 40.0 & 3 & 5.0 & 21.08 & $<0.001 *$ \\
\hline WBC & 11 & 18.3 & 0 & 0.0 & 12.11 & $0.001 *$ \\
\hline Platelets & 1 & 1.7 & 1 & 1.7 & Fisher & 1.00 \\
\hline Bilirubin (total) & 26 & 43.3 & 6 & 10.0 & 17.05 & $<0.001 *$ \\
\hline Bilirubin (direct) & 4 & 6.7 & 1 & 1.7 & Fisher & 0.36 \\
\hline \multicolumn{7}{|l|}{ Physiologically adapted: } \\
\hline No & 57 & 95.0 & 20 & 33.3 & & $<0.001 *$ \\
\hline Yes & 3 & 5.0 & 40 & 66.7 & 49.62 & \\
\hline
\end{tabular}

(*) Statistically significant at $p<0.05$

Table 3: Relation between physiological adaptation of preterm infants on Day 6 and their mothers' personal, medical, and obstetric history

\begin{tabular}{|c|c|c|c|c|c|c|}
\hline \multirow[t]{3}{*}{ Mother } & \multicolumn{4}{|c|}{ Physiologically adapted } & \multirow[t]{3}{*}{$\mathrm{X}^{2}$ test } & \multirow[t]{3}{*}{ p-value } \\
\hline & \multicolumn{2}{|c|}{ No $(n=20)$} & \multicolumn{2}{|c|}{ Yes $(n=40)$} & & \\
\hline & No. & $\%$ & No. & $\%$ & & \\
\hline \multicolumn{7}{|l|}{ Age: } \\
\hline$<35$ & 14 & 70.0 & 32 & 80.0 & & \multirow[t]{2}{*}{0.52} \\
\hline $35+$ & 6 & 30.0 & 8 & 20.0 & Fisher & \\
\hline \multicolumn{7}{|l|}{ Education: } \\
\hline Illiterate & 5 & 25.0 & 17 & 42.5 & & \multirow[t]{3}{*}{0.30} \\
\hline Basic & 5 & 25.0 & 5 & 12.5 & 2.44 & \\
\hline Secondary & 10 & 50.0 & 18 & 45.0 & & \\
\hline \multicolumn{7}{|l|}{ Job status: } \\
\hline Housewife & 13 & 65.0 & 30 & 75.0 & & \multirow[t]{2}{*}{0.42} \\
\hline Working & 7 & 35.0 & 10 & 25.0 & 0.66 & \\
\hline \multicolumn{7}{|l|}{ BMI: } \\
\hline Normal $(<25)$ & 7 & 35.0 & 16 & 40.0 & & \multirow[t]{3}{*}{0.93} \\
\hline Overweight $(25-<30)$ & 8 & 40.0 & 15 & 37.5 & 0.14 & \\
\hline Obese $(30+)$ & 5 & 25.0 & 9 & 22.5 & & \\
\hline \multicolumn{7}{|l|}{ Gravidity: } \\
\hline 1 & 4 & 20.0 & 11 & 27.5 & & \multirow[t]{3}{*}{0.74} \\
\hline $2-3$ & 10 & 50.0 & 20 & 50.0 & 0.60 & \\
\hline $4+$ & 6 & 30.0 & 9 & 22.5 & & \\
\hline Previous abortions & 10 & 50.0 & 8 & 20.0 & 5.71 & $0.02 *$ \\
\hline \multicolumn{7}{|l|}{ History of: } \\
\hline Preterm labor & 5 & 25.0 & 7 & 17.5 & Fisher & 0.51 \\
\hline
\end{tabular}


Physiological Adaptation among Preterm Infants and Associated Maternal Factors

\begin{tabular}{|l|r|r|r|r|r|c|}
\hline Stillbirth & 9 & 45.0 & 8 & 20.0 & 4.10 & $0.04^{*}$ \\
\hline Cesarean section & 7 & 35.0 & 14 & 35.0 & 0.00 & 1.00 \\
\hline Incompetence & 2 & 10.0 & 0 & 0.0 & Fisher & 0.11 \\
\hline PROM & 11 & 55.0 & 21 & 52.5 & 0.03 & 0.85 \\
\hline DM & 2 & 10.0 & 2 & 5.0 & Fisher & 0.59 \\
\hline
\end{tabular}

(*) Statistically significant at $p<0.05$

(--) Test result not valid

Table 4: Relation between physiological adaptation of infants on Day 6 and their mothers' current pregnancy and labor characteristics

\begin{tabular}{|c|c|c|c|c|c|c|}
\hline \multirow[t]{3}{*}{ Mother } & \multicolumn{4}{|c|}{ Physiologically adapted } & \multirow[t]{3}{*}{$\mathrm{X}^{2}$ test } & \multirow[t]{3}{*}{ p-value } \\
\hline & \multicolumn{2}{|c|}{ No $(n=20)$} & \multicolumn{2}{|c|}{ Yes $(n=40)$} & & \\
\hline & No. & $\%$ & No. & $\%$ & & \\
\hline \multicolumn{7}{|l|}{ Gestational weeks: } \\
\hline$<32$ & 1 & 5.0 & 1 & 2.5 & & \multirow[t]{3}{*}{0.67} \\
\hline $32-35$ & 14 & 70.0 & 32 & 80.0 & 0.80 & \\
\hline $36+$ & 5 & 25.0 & 7 & 17.5 & & \\
\hline Multiple pregnancies & 0 & 0.0 & 11 & 27.5 & Fisher & $0.01 *$ \\
\hline \multicolumn{7}{|c|}{ Weight gain in pregnancy $(\mathrm{kg})$ : } \\
\hline$<10$ & 12 & 60.0 & 19 & 47.5 & & \multirow[t]{3}{*}{0.59} \\
\hline $10-11$ & 3 & 15.0 & 10 & 25.0 & 1.05 & \\
\hline $12+$ & 5 & 25.0 & 11 & 27.5 & & \\
\hline \multicolumn{7}{|l|}{ Pregnancy complications: ${ }^{@}$} \\
\hline Urinary tract infection & 13 & 65.0 & 25 & 62.5 & 0.04 & 0.85 \\
\hline Vaginal infection & 12 & 60.0 & 27 & 67.5 & 0.33 & 0.57 \\
\hline Polyhydramnios & 4 & 20.0 & 6 & 15.0 & Fisher & 0.72 \\
\hline Oligohydramnios & 2 & 10.0 & 6 & 15.0 & Fisher & 0.71 \\
\hline Hypertension & 6 & 30.0 & 3 & 7.5 & Fisher & $0.049 *$ \\
\hline GDM & 6 & 30.0 & 8 & 20.0 & Fisher & 0.52 \\
\hline Vaginal bleeding (APH) & 9 & 45.0 & 21 & 52.5 & 0.30 & 0.58 \\
\hline Hyperemesis gravidarum & 3 & 15.0 & 13 & 32.5 & 2.09 & 0.15 \\
\hline Anemia during pregnancy & 8 & 40.0 & 16 & 40.0 & 0.00 & 1.00 \\
\hline Had any complications & 20 & 100.0 & 37 & 92.5 & Fisher & 0.54 \\
\hline \multicolumn{7}{|l|}{ Pregnancy spacing (months): } \\
\hline$<24$ & 15 & 75.0 & 20 & 50.0 & & \multirow[t]{2}{*}{0.06} \\
\hline $24+$ & 5 & 25.0 & 20 & 50.0 & 3.43 & \\
\hline \multicolumn{7}{|l|}{ Mode of labor: } \\
\hline Vaginal & 11 & 55.0 & 17 & 42.5 & & \multirow[t]{2}{*}{0.36} \\
\hline Cesarean section & 9 & 45.0 & 23 & 57.5 & 0.84 & \\
\hline \multicolumn{7}{|l|}{ Newborn gender: } \\
\hline Male & 13 & 65.0 & 17 & 42.5 & & \multirow[t]{2}{*}{0.10} \\
\hline Female & 7 & 35.0 & 23 & 57.5 & 2.70 & \\
\hline
\end{tabular}

(*) Statistically significant at $p<0.05$

@ Numbers are mutually exclusive

Table 5: Best fitting multiple logistic regression model for the occurrence of physiological adaptation among preterm infants

\begin{tabular}{|c|c|c|c|c|c|c|}
\hline & \multirow[t]{2}{*}{ Wald } & \multirow[t]{2}{*}{ Df } & \multirow[t]{2}{*}{$\mathrm{P}$} & \multirow[t]{2}{*}{ OR } & \multicolumn{2}{|c|}{$\begin{array}{c}95.0 \% \mathrm{CI} \\
\text { for OR }\end{array}$} \\
\hline & & & & & Upper & Lower \\
\hline Constant & 4.42 & 1 & .035 & .60 & & \\
\hline Previous abortion & 4.38 & 1 & .036 & .37 & .15 & .94 \\
\hline Multiple pregnancy & 3.96 & 1 & .047 & 2.36 & 1.01 & 5.48 \\
\hline \multicolumn{7}{|c|}{ Nagelkerke R Square: 0.10} \\
\hline \multicolumn{7}{|c|}{ Hosmer and Lemeshow Test: $\mathrm{p}=0.762$} \\
\hline \multicolumn{7}{|c|}{ Omnibus Tests of Model Coefficients: $\mathrm{p}<0.001$} \\
\hline
\end{tabular}

\section{Discussion}

The present study findings point to significant improvements in preterm infants' physiological adaptation along their first six-day age follow-up. Only two factors of the current pregnancy have a significant influence on this improvement. Meanwhile, none of the other maternal factors had any independent effect on it. According to the present study findings, the preterm infants' physiological adaptation improved significantly between their first and sixth days of life. This was demonstrated by the normalization of their systolic and diastolic blood pressure levels. This might be a good indicator of the preterm infant's adjustment to the extrauterine environment, and is due to the intensive care interventions to maintain fetal circulation close to normal. Nonetheless, the values of systolic and diastolic blood pressure are not the only indicators of the newborn's hemodynamic status since blood pressure is a dependent factor on the heart rate and cardiac output, which may compensate each other; additionally, it is not a good indicator of tissue perfusion in various body organs ${ }^{[25]}$. 
However, the general improvements in all parameters among the present study preterm infants may reflect improvements of their hemodynamics. These are certainly due to the highly specialized care provided in the properly equipped high-risk neonatal unit, with most advanced technology, highly qualified nurses, and high nurse patient ratio.

Furthermore, the present study findings indicate significant improvements in preterm infant respiratory functions, with marked decreases in the percentages of those suffering from respiratory distress syndrome (RDS) by the sixth day of life. This is certainly attributed to the intensive management with routine administration of steroids 48 hours before delivery, and of surfactant administration to the preterm infant, in addition to oxygen administration. According to ${ }^{[26]}$, this combination has synergistic effect on the lungs of the preterm infant. It led to significant improvements in respiratory functions, with decreases in morbidity and mortality rates. Nonetheless, a recent study in Australia revealed that the oxygen saturation response of the preterm infant is influenced by the severity of the respiratory disorders, in addition to certain individual variability among these preterm infants ${ }^{[27]}$.

The growth parameters, as indicated by the anthropometric measurements, have demonstrated significant improvements among the preterm infants of the current study. Thus, by the sixth day, one-half of them reached to normal body weight and length. This is certainly due to thorough continuous assessment of preterm infant feeding abilities and handicaps, and to the nurses' planning according to individual problems of each infant. The finding is an extremely important one given the effect of growth at this stage of infant life on anthropometric parameters at later age. In this respect, a study in France ${ }^{[28]}$ concluded that the growth rate during the neonatal period is significantly and positively related to the length at the age of two years. This indicates the importance of giving close attention to these parameters in pre-term care. Approaches to special types of feeding of preterm infants with adjusted administration of lipids and amino acids ${ }^{[29]}$, as well as increasing skin-to-skin contact between mother and infant ${ }^{[30]}$ proved to be effective in enhancing their growth at this critical stage of their lives. Nonetheless, a recent systematic review ${ }^{[31]}$ concluded that although normative growth parameters are available for healthy term infants, they are very limited for preterm infants.

The present study identified multiple pregnancies as a factor independently favoring the physiological adaptation of the preterm infant. Thus, the odds of this adaptation in a twin pregnancy are 2.36 folds the odds in a singleton pregnancy. This might be explained by that twin pregnancy, as a factor underlying preterm delivery, is a physiological rather than a pathological one. Thus, it could be the sole cause of prematurity, and the infants may have a higher probability of lack of other pathological factors. The finding is in agreement with ${ }^{[32]}$ whose study in Slovenia demonstrated significantly more perinatal complications among singleton infants in comparison with twins. On the same line, a study in the Netherlands reported a significantly lower mortality rate among twin preterm infants compared with singletons ${ }^{[33]}$.

On the other hand, a history of previous abortion among the mothers of the current study preterm infants was identified as a risk factor independently influencing physiological adaptation among them. Their odds of adaptation are almost one third in comparison to those born to mothers lacking such history. This might be attributed to the factors that led to the previous abortions, and which could still exist. The finding is in congruence with the results of previous studies indicating that abortion increases the risk of prematurity ${ }^{[34]}$ [35]. Moreover, a Finnish study reported a dose-response relationship between induced abortions and later adverse birth outcomes ${ }^{[36]}$. Nonetheless, a mother with previous history of abortion might have a higher tendency to seek antenatal care and comply with pertinent instructions. This has been shown in a study in the United States, where the mothers with history of adverse pregnancy outcomes had a higher and better utilization of preconception care $^{[37]}$.

According to the present study findings, there was a trend of better physiological adaptation among the female preterm infants compared with the male ones. However, the difference was not statistically significant probably due to the small sample size as this issue was not one of the main study objectives. The finding is in agreement with previous literature, and is often attributed to the higher susceptibility of male preterm infants to the respiratory distress syndrome problem ${ }^{[38]}$. This gender difference has been reduced by the use of continuous positive airway pressure ${ }^{[39]}$. Therefore, the issue may need further study with a suitable sample size.

\section{Conclusion And Recommendations}

In conclusion, approximately two-thirds of the preterm infants in the study setting had good physiological adaptation by their sixth day of life. The twin pregnancy seems to favor such adaptation, whereas a maternal history of abortion is a risk factor that may hinder it. The study recommended that, more attention is to be paid to those infants delivered to mothers with a history of abortion, especially if singleton. The difference in adaptation between boys and girls needs further study with suitable sample size. 


\section{References}

[1]. Lisonkova S., Sabr Y., Butler B., and Joseph K.S. International comparisons of preterm birth: higher rates of late preterm birth are associated with lower rates of stillbirth and neonatal death. BJOG; 119 (13), 2012,1630-9. doi: 10.1111/j.1471-0528.2012.03403.x.

[2]. WHO, Data WLC-I-P (ed.). Born Too Soon: The Global Action Report on Preterm Birth. Geneva: World Health Organisation , 2012.

[3]. Loftin R., Habli, M., Snyder C., Cormier C., Lewis D., and DeFranco E.Winter Late Preterm Birth. Rev Obstet Gynecol.; 3(1), 2010, 10-19.

[4]. National Institute of Child Health and Human Development , "Preterm Labor and Birth: Condition Information". http://www.nichd.nih.gov. 03/11/2014. Retrieved 7 March 2015.

[5]. Haas D.M., Morgan A.M., Deans S.J., and Schubert F.P. Ethanol for preventing preterm birth in threatened preterm labor. Cochrane Database Syst Rev.;(11), 2015, CD011445. doi: 10.1002/14651858.CD011445.pub2.

[6]. Buhimschi C., and Norman J.E Pathogenesis of spontaneous preterm labor. In Creasy RK, Resnik R, Iams JD, Lockwood CJ, Moore TR, Greene MF, eds. Creasy and Resnik's maternal fetal medicine: principles and practice. $7^{\text {th }}$ ed., Philadelphia: Saunders/Elsevier, 2013, pp. 599-623.

[7]. Blencowe H., Cousens S., Chou D., Oestergaard M., and Say L. National, regional, and worldwide estimates of preterm birth rates in the year 2010 with time trends since 1990 for selected countries: a systematic analysis and implications. The Lancet; 379, 2012, 2162-2172.

[8]. Oshiro B.T., Kowalewski L., and Sappenfield W. A multistate quality improvement program to decrease elective deliveries before 39 weeks of gestation. Obstet Gynecol;121, 2013, 1025-1031.

[9]. Beck S., Wojdyla D., Say L., Pilar A., Merialdi M., Requejo J., Rubens C., Menonf R., and Van P. The worldwide the worldwide incidence of preterm birth: a systematic review of maternal mortality and morbidity. Bull 31 World Health Organization,88, 2010; 31-38.

[10]. Alabbasi K.H., Kruger E., and Tennant M. 'Maternal variables as potential modifiable risk indicators of preterm labor in Jeddah, Saudi Arabia' Journal of Pregnancy and Child Health;02(03), 2015, 1-4.

[11]. Khalil A., Syngelaki A., Maiz N., Zinevich Y., and Nicolaides K.H. Maternal age and adverse pregnancy outcome: a cohort study. Ultrasound in Obstetrics and Gynecology.;42(6), 2013, 634-43.

[12]. Mohammad K.I., Abu Dalou A., Kassab M., Gamble J., and Creedy D. Prevalence and factors associated with the occurrence of preterm birth in Irbid governorate of Jordan: A retrospective study. International Journal of Nursing Practice; 21, 2015, 505-510

[13]. Cnattingius S., Villamor E., Johansson S., Bonamy A-K., Persson M., Wikström A-K., and Granath F. Maternal Obesity and Risk of Preterm Delivery. The Journal of American Medical Association (JAMA).; 309(22), 2013, 2362-237.

[14]. Goldenberg R.L., Culhane J.F., Iams J.D., and Romero R. Epidemiology and causes of preterm birth. Lancet;371, 2008, 75-84

[15]. Wu T.W., Azhibekov T., and Seri I. Transitional Hemodynamics in Preterm Neonates: Clinical Relevance. Pediatr Neonatol.;57(1), 2016, 7-18. doi: 10.1016/j. pedneo.2015.07.002. Epub 2015 Aug 29.

[16]. Rochow N., Raja P., Liu K., Fenton T., Landau-Crangle E., Göttler S., Jahn A., Lee S., Seigel S., Campbell D., Heckmann M., and Pöschl J., and Fusch C. Physiological adjustment to postnatal growth trajectories in healthy preterm infants. Pediatr Res.;79(6), 2016, 870-9. doi: 10.1038/pr.2016.15.

[17]. Guasti L., Silvennoinen S., Bulstrode N.W., Ferretti P., Sankilampi U., and Dunkel L. (2014): Elevated FGF21 leads to attenuated postnatal linear growth in preterm infants through GH resistance in chondrocytes. J Clin Endocrinol Metab.;99(11), 2014, E2198206. doi: 10.1210/jc.2014-1566.

[18]. Hussain S.M., Kähönen M., Raitakari O.T., Skilton M.R., Witt N., Chaturvedi N., Hutri-Kähönen N., Lehtimäki T., VaahtorantaLehtonen H., Juonala M., Wijetunge S., Hughes A.D., McG Thom S.A., Metha A., and Tapp R.J. Impact of fetal growth and preterm birth on the retinal microvasculature in mid-adulthood. Microcirculation.;22(4), 2014, 285-93. doi: 10.1111/micc.12197.

[19]. Flensborg-Madsen T., Revsbech R., Sørensen H.J., and Mortensen E.L. An association of adult personality with prenatal and early postnatal growth: the EPQ lie-scale. BMC Psychol.;2(1), 2014, 8. doi: 10.1186/2050-7283-2-8. eCollection 2014.

[20]. Murray E., Pearson R., Fernandes M., Santos I.S., Barros F.C., Victora C.G., Stein A., and Matijasevich A. Are fetal growth impairment and preterm birth causally related to child attention problems and ADHD? Evidence from a comparison between highincome and middle-income cohorts. J Epidemiol Community Health.;70(7), 2016, 704-9. doi: 10.1136/jech-2015-206222. Epub 2016 Jan 13

[21]. Pieltain C., de Halleux V., Senterre T., and Rigo J. Prematurity and bone health. World Rev Nutr Diet. 2013;106:181-8. doi: $10.1159 / 000342680$.

[22]. Hoyme U.B. Pragmatic prevention of preterm birth and evidence based medicine. Arch Gynecol Obstet.;294(1), 2016, 1-3. doi: 10.1007/s00404-016-4094-x.

[23]. Hockenberry M., and Wilson D. Wong's Essentials of Pediatric Nursing, $9^{\text {th }}$.ed., St. Louis, El Sevier, 2013.

[24]. Pillitteri A. Maternal and Child Health Nursing: Care of the Childbearing and Childbearing Family, 7th.ed., Wolters kluwer, Lippincott, 2014.

[25]. Wu T.W., Noori S., and Seri I. Neonatal hypotension. In: Polin RA, Yoder MC, editors. Workbook in practical neonatology. 5th ed., Philadelphia: Elsevier/Saunders, p. 230e43, 2014.

[26]. Warren J.B., and Anderson J.M. (2009): Core concepts: respiratory distress syndrome,In Hockenberry, M \& Wilson, D. (eds.). Wong's Essentials of Pediatric Nursing, $9^{\text {th }}$ ed., 2013, St. Louis: El Sevier.

[27]. Sadeghi Fathabadi O., Gale T.J., Lim K., Salmon B.P., Dawson J.A., Wheeler K.I., Olivier J.C., and Dargaville P.A. Characterization of the Oxygenation Response to Inspired Oxygen Adjustments in Preterm Infants. Neonatology; 109(1), 2016, 3743. doi: 10.1159/000440642. Epub 2015 Nov 11.

[28]. Goisbault M., Simon L., Hanf M., Darmaun D., Rozé J.C., and Flamant C. Neonatal Length Growth and Height at Two Years. Neonatology.;110(2), 2016, 125-8. doi: 10.1159/000444473. Epub 2016 Apr 18.

[29]. Törer B., Hanta D., Özdemir Z., Çetinkaya B., and Gülcan H. An aggressive parenteral nutrition protocol improves growth in preterm infants. Turk J Pediatr.;57(3),2015, 236-41.

[30]. Moore E.R., Anderson G.C., Bergman N., and Dowswell T. Early skin-to-skin contact for mothers and their healthy newborn infants. Cochrane Database Syst Rev.;(5), 2012, CD003519. doi: 10.1002/14651858. CD003519. pub3.

[31]. Griffin L. Literature review: Growth management in preterm infants Updated at Apr 6, 2016. http://www.uptodate.com/contents/growth-management-in-preterm-infants Accessed at 16/7/2016.

[32]. Lucovnik M., Tul N., Verdenik I., and Blickstein I. Perinatal outcomes in singleton and twin pregnancies following first-trimester bleeding. J Perinatol.;34(9), 2014, 673-6. doi: 10.1038/jp.2014.74. Epub 2014 May 1.

DOI: $10.9790 / 1959-0601023138 \quad$ www.iosrjournals.org

$37 \mid$ Page 
[33]. Vasak B., Verhagen J.J., Koenen S.V., Koster M.P., de Reu P.A., Franx A., Nijhuis J.G., Bonsel G.J., and Visser G.H. Lower perinatal mortality in preterm born twins than in singletons; a nationwide study from the Netherlands. Am J Obstet Gynecol. S00029378(16), 2016, 30868-7. doi: 10.1016/j.ajog.2016.10.005. [Epub ahead of print]

[34]. Abdelhady A., and Abdelwahid A: Rate and Risk Factors of Preterm Births in a Secondary Health Care Facility in Cairo. World Journal of Medical Sciences; 12 (1), 2015, 09-16.

[35]. Oliver-Williams C., Fleming M., Wood A.M., and Smith G.C.S. Previous miscarriage and the subsequent risk of preterm birth in Scotland, 1980-2008: a historical cohort study, 2015.

[36]. Klemetti R., Gissler M., Niinimäki M., and Hemminki E. Birth outcomes after induced abortion: a nationwide register-based study of first births in Finland. Hum Reprod.;27(11), 2012, 3315-20. doi: 10.1093/humrep/des294. Epub 2012 Aug 29.

[37]. Batra P., Higgins C., and Chao S.M. Previous Adverse Infant Outcomes as Predictors of Preconception Care Use: An Analysis of the 2010 and 2012 Los Angeles Mommy and Baby (LAMB) Surveys. Matern Child Health J.;20(6), 2016, 1170-7. doi: 10.1007/s10995-015-1904-x.

[38]. Ishak N., Sozo F., Harding R., De and Matteo R. Does lung development differ in male and female fetuses? Exp Lung Res.;40(1), 2014,30-9. doi: 10.3109/01902148.2013.858197. Epub 2013 Dec 19.

[39]. De Matteo R., Ishak N., Hanita T., Harding R., and Sozo F. Respiratory adaptation and surfactant composition of unanesthetized male and female lambs differ for up to $8 \mathrm{~h}$ after preterm birth. Pediatr Res.;79(1-1), 2016, 13-21. doi: 10.1038/pr.2015.175. Epub 2015 Sep 15 